\title{
Determination of free and total phthalates in commercial whole milk products in different packaging materials by gas chromatography-mass spectrometry
}

\author{
Jialu Lin, Wanxin Chen, Hangcui Zhu, and Chengjun Wang ${ }^{1}$ \\ College of Chemistry and Materials Engineering, Wenzhou University, Wenzhou 325035, China
}

\begin{abstract}
We developed a method for extraction and determination of free and total phthalate esters in commercial whole milk products. The free phthalates in milk samples were extracted with ethyl acetate after general pretreatment procedures including protein precipitation, centrifugation, and filtration. The bound phthalates in samples were first desorbed with the aid of ultrasound irradiation before extraction of total phthalates. The separation and determination of phthalates in extracts was performed by gas chromatography coupled with mass spectrometric detection. The detection limits were in the range of 0.09 to $0.36 \mathrm{ng} / \mathrm{g}$ and the average recovery between 79.1 and $110.3 \%$. The developed methods were applied to extract and determine phthalates in commercial whole milk products with different packaging materials, including plastic, glass, and metal. All samples contained several phthalates, including diethyl, diisobutyl, and bis(2-ethylhexyl) phthalates at concentrations between 2.60 and $156.4 \mathrm{ng} / \mathrm{g}$. The identified phthalates occurred in both free and bound forms. The amounts of phthalates in milk samples packaged in glass and metal containers were much lower than those in plastic containers. Plastic packaging materials are a possible source of phthalate contamination in commercial whole milk products, and a considerable portion of bleached phthalates from packaging can be adsorbed on proteins and other solid components of milk.
\end{abstract}

Key words: phthalate, milk product, bound form, gas chromatography-mass spectrometry

\section{INTRODUCTION}

Phthalate esters are used primarily as plasticizers in polymeric materials to increase their flexibility through weak secondary molecular interactions with polymer chains. Because they are physically bound to the polymer chains, phthalate esters may migrate into foods during food processing and storage in plastic packing

Received July 5, 2015.

Accepted August 26, 2015.

${ }^{1}$ Corresponding author: wang.chengjun@yahoo.com materials (Fasano et al., 2012). These compounds are listed as suspected endocrine disrupters or mutagens, which can have adverse effects on human health even at low levels (Hauser et al., 2007; Kamrin, 2009; Kimber and Dearman, 2010; López-Carrillo et al., 2010; Ferguson et al., 2011; Hu et al., 2013; Ventrice et al., 2013). Because it contains abundant vitamins, minerals, carbohydrates, lipids, and proteins, which are essential for human health, milk is considered one of the most nutritionally complete natural foods (Jenkins and McGuire, 2006; Soyeurt et al., 2010). Many specialized milk products such as cheese, yogurt, butter, and ice cream are popular in diets worldwide. However, most commercial milk products are packaged in plastic or other polymer materials. Therefore, it is extremely important for human health protection to evaluate and monitor phthalates in commercial milk products.

Recently, many studies have reported analysis of phthalates in milk or other food samples (Casajuana and Lacorte, 2004; Carrillo et al., 2007; Cao, 2008; Guo et al., 2012; Hsieh et al., 2013; Jia et al., 2014; Van Holderbeke et al., 2014). In general, techniques such as extraction with solvents and solid phase extraction are used to clean up and concentrate the milk samples before analysis. Following sample extraction or enrichment, GC-MS and HPLC-MS have been exclusively used for the separation and detection of phthalates (Feng et al., 2005; Feás et al., 2008; Guo, 2008; Xu et al., 2014). The HPLC-MS method is used less often than GC-MS, possibly because it uses more potential contamination sources such as plastic filters, tubing, and solvents for the mobile phase (Khedr, 2013). Although these methods have been successfully applied for the analysis of phthalates in whole milk and derivative products, most studies determined only free phthalates that occurred in solution of milk samples. However, a few studies have indicated that phthalates are highly hydrophobic and easily adsorbed onto the surface of proteins and lipids (Abraham and Acree, 2015). Theoretically, part of the migrated phthalates could exist as bound forms in milk products, and those phthalates should be measured to avoid underestimation of the total concentration of phthalates in milk samples. The adsorbed phthalates should be desorbed from the surface of proteins and 
lipids in milk samples before the general pretreatment and preconcentration procedures.

The main objective of this work was to develop a method for extraction and determination of free and bound phthalate esters in milk samples, and to apply the developed method to evaluate free and bound phthalates in selected commercial whole milk products packaged in plastic, glass, and metal materials.

\section{MATERIALS AND METHODS}

\section{Chemicals and Standards}

Standards of the individual phthalate esters [dimethyl phthalate (DMP), diethyl phthalate (DEP), diallyl phthalate (DAP), diisobutyl phthalate (DIBP), dibutyl phthalate (DBP), benzyl butyl phthalate (BBP), dicyclohexyl phthalate (DCHP), bis(2-ethylhexyl) phthalate (DEHP), di-n-octyl phthalate (DNOP)] used for this study were purchased from Tokyo Kasei Kogyo Co. Ltd. (Shanghai, China). The HPLC-grade methanol and ethyl acetate were obtained from Tjshield Chemicals (Tianjin, China). Hydrochloric acid, sulfuric acid, glacial acetic acid, and magnesium sulfate were supplied by Zhejiang Zhongxing Chemical Reagent Co. Ltd. (Jinhua, China). All solvents and reagents used in this study were of analytical grade unless otherwise specified. All water and reagents were checked for contamination with phthalates before use. A mixed standard stock solution $(50.0 \mathrm{mg} / \mathrm{mL})$ containing the 9 phthalates was prepared in anhydrous methanol and stored at $4^{\circ} \mathrm{C}$ in the dark. The working standard solutions were prepared freshly in methanol at concentrations of $0.00,5.00,10.0,25.0$, and $50.0 \mathrm{mg} / \mathrm{L}$ by diluting the stock standard solution.

\section{Sample Preparation}

Three milk samples with different package materials - metal, glass, and plastic - were purchased from a local supermarket and stored at $4^{\circ} \mathrm{C}$ until used in this study. Before extraction of free phthalates, the proteins and lipids in milk samples need to be removed because those components could affect extraction efficiency and interfere with the instrumental analysis. In detail, a milk sample $(5.0 \mathrm{~mL})$ was pipetted into a $10-\mathrm{mL}$ glass centrifuge tube; then, $1.0 \mathrm{~mL}$ of $10 \%$ (vol/vol) acetic acid was added, mixed well, and heated in a sand bath at $70^{\circ} \mathrm{C}$ for $10 \mathrm{~min}$. The mixture was then cooled to room temperature and centrifuged for $10 \mathrm{~min}$ at 1,500 $\times g$. An aliquot of the supernatant was decanted out and filtered through a $0.45-\mu \mathrm{m}$ nylon filter membrane. Then, $5 \mathrm{~mL}$ of filtrate was pipetted into a $10-\mathrm{mL}$ glass vial and extracted with $1.0 \mathrm{~mL}$ of ethyl acetate
3 times. The ethyl acetate extracts were combined, passed through anhydrous $\mathrm{MgSO}_{4}$ packed in a Pasteur pipet to remove the residual water, and collected into a 5 -mL glass vial. The extracts were then completely dried under a stream of nitrogen gas. Finally, $0.5 \mathrm{~mL}$ of methanol was added and vortexed for $1.0 \mathrm{~min}$ and the solution was transferred into a clean 2 -mL mini-vial for instrumental analysis.

To analyze the total phthalates in milk samples, the bound phthalates adsorbed on the proteins and other solid components must be desorbed before pretreatment to remove general protein and lipids. Previously, ultrasonic radiation, a type of low frequency energy, was extensively studied for improving almost all sample preparation and pretreatment processes, including cleaning, degassing, digestion, leaching, crystallization, precipitation, and extraction (Shen, 2005; Zuo et al., 2008; Wang and Zuo, 2011). In this study, milk samples $(5.0 \mathrm{~mL})$ were first added to $1.0 \mathrm{~mL}$ of $10 \%$ (vol/vol) acetic acid and pretreated using ultrasonic irradiation generated by an ultrasound producer (model AS20500BDT with digital timer, heat and power control, Automatic Science Instrument, Tianjin, China) at $60^{\circ} \mathrm{C}$ for $30 \mathrm{~min}$. Then, the samples were centrifuged, filtered, extracted, dried, redissolved, and transferred for instrumental analysis as described for extraction of free phthalates.

\section{Analytical Methods}

Instrumental analysis was carried out on a Shimadzu GCMS-QP2010 plus gas chromatography-mass spectrometer equipped with an auto-sampler (Shimadzu, Tokyo, Japan). The phthalate compounds in standards and extracts of milk samples were separated on a 30 $\mathrm{m} \times 0.32 \mathrm{~mm}$ i.d., $0.25-\mu \mathrm{m}$ film DB-5 fused-silica capillary column (J\&W Scientific, Folsom, CA). The column temperature was initially held at $120^{\circ} \mathrm{C}$ for 4 min, and then programmed to $220^{\circ} \mathrm{C}$ at a rate of $5^{\circ} \mathrm{C}$ per min, from $220^{\circ} \mathrm{C}$ to $300^{\circ} \mathrm{C}$ at a rate of $20^{\circ} \mathrm{C}$ per min, and with a final hold time of $6 \mathrm{~min}$. Helium was used as the carrier gas and the column head pressure maintained at $14.5 \mathrm{psi}(\sim 100 \mathrm{kPa})$. The injector and detector temperature were maintained at $280^{\circ} \mathrm{C}$ and $305^{\circ} \mathrm{C}$, respectively, and the injection volume was $2 \mu \mathrm{L}$ with splitless mode; electron impact ionization energy was $70 \mathrm{eV}$.

\section{RESULTS AND DISCUSSION}

\section{Method Evaluation}

The phthalates in extracts of milk samples were identified by matching GC retention times against 
those of standards and by comparing the mass spectra with authentic standards. A total ion chromatogram obtained from a $25 \mathrm{mg} / \mathrm{L}$ mixture of 9 phthalate standards is shown in Figure 1A. The peaks were sharp and symmetrical and good separation of the 9 analytes was achieved. All quantification was performed by an external calibration method based on peak areas. Calibration curves were constructed by linear regression of the peak area versus standard concentrations. Standards mixtures of the 9 phthalate compounds in a concentration range of 0.00 to $50.0 \mathrm{mg} / \mathrm{L}$ were prepared for calibration curves. All calibration standards and extracts of samples were run in triplicate. The retention times, calibration curve equations, and coefficients, identified ions (mass-to-charge ratio, $\mathrm{m} / z$ ), and detection limits are listed in Table 1. All calibration curves were linear over the concentration ranges tested, with correlation coefficients $>0.99$. The detection limits examined at 3 times the background noise ranged from 0.09 to 0.36 $\mathrm{ng} / \mathrm{g}$, and the corresponding limits of quantification ranged from 0.3 to $1.2 \mathrm{ng} / \mathrm{g}$ for all compounds. To decrease the possibility of laboratory contamination with phthalates, glass containers, centrifuge tubes, and vials were used during the preparation of standards and samples. The concentrations of the phthalates of interest in blank samples were less than their corresponding detection limits under current experimental conditions by analyzing the pure water sample; this indicates that there was no significant contamination of phthalates during the sample pretreatment process. The described method was tested in commercial milk matrices with known amounts of 9 phthalate standards added, and these spiked samples were subjected to the entire analytical procedure from sample pretreatment to chromatographic analysis. The recoveries, expressed as the mean percentage ratio between the amounts found and those added, were 79.1 to $110.3 \%$ in different milk samples, as presented in Table 2. Day-to-day precision was evaluated by performing 6 injections of standard solutions and milk samples each day on 5 different days within a 2 -wk period. Inter-day precision (relative standard deviation, RSD) based on retention time and peak area was lower than $3.5 \%$. Repeatability of the method was performed by 3 analysts ( 6 determinations by each analysts) using the described method and the same instrument. The results showed no significant differences (RSD <8.6\%).

\section{Analysis of Real Milk Samples}

Milk is probably the most nutritionally complete food found in nature and it contains about $87.1 \%$ water, $0.7 \%$ minerals, $3.4 \%$ proteins, $4.9 \%$ carbohydrates, and
$3.9 \%$ lipids. Because of the complex matrix effects of whole milk samples, some pretreatment is necessary to remove protein and lipids, decrease matrix suppression (i.e., suppression of detection signals of target analytes by other components in samples due to the complex sample matrix), protect the analytical column, and improve detection sensitivity. Many deproteinization methods have been reported, such as adding organic solvents and acids (e.g., methanol, acetonitrile, or perchloric, trichloroacetic, and acetic acids) during sample pretreatment (Fritz and Zuo, 2007; Zhang et al., 2013; Zuo et al., 2015). In the present study, we precipitated protein with acetic acid, which could facilitate the subsequent liquid-liquid extraction by using ethyl acetate as the extract solvent compared with other organic solvents as deproteinization reagents. On the other hand, phthalates are highly hydrophobic compounds and easily bound to proteins and lipids. The general deproteinization process could cause loss of phthalates with the removal of proteins and lead to an underestimation of total phthalate concentrations in the samples. Thus, the bound phthalates on the surface of the proteins were desorbed with the aid of ultrasonic irradiation before deproteinization of the milk samples.

The method described in this study was applied to extract and determine free and bound phthalates in commercial whole milk products in different packaging materials (i.e., plastic, glass, and metal). Typical chromatograms for a milk sample in a plastic container without and with ultrasonic treatment are illustrated in Figure 1B and 1C. Individual analytes were identified by matching retention times and mass-to-charge ratios of ions against those of authentic standards, as presented in Figure 2, and by spiking milk samples with the standard of each analyte. The concentrations of free and bound phthalates in the milk samples are given in Table 3. All samples contained several phthalates, including DEP, DIBP, and DEHP at concentrations between 2.60 and $156.4 \mathrm{ng} / \mathrm{g}$. Phthalates DIBP and DEHP occurred in both free and bound forms, whereas DEP only occurred in bound forms, possibly because of the extremely low solubility of DEP in aqueous solution (Abraham and Acree, 2015). A potential source of identified phthalates in milk samples packaged in metal and glass containers may be the milk, with phthalates originating from environmental contamination, uptake, and accumulation by animals (Fierens et al., 2012). However, the amounts of phthalates were much higher in milk samples packaged in plastic containers compared with glass or metal containers, indicating that plastic packaging materials are the likeliest source of phthalate contamination in commercial whole milk products. 


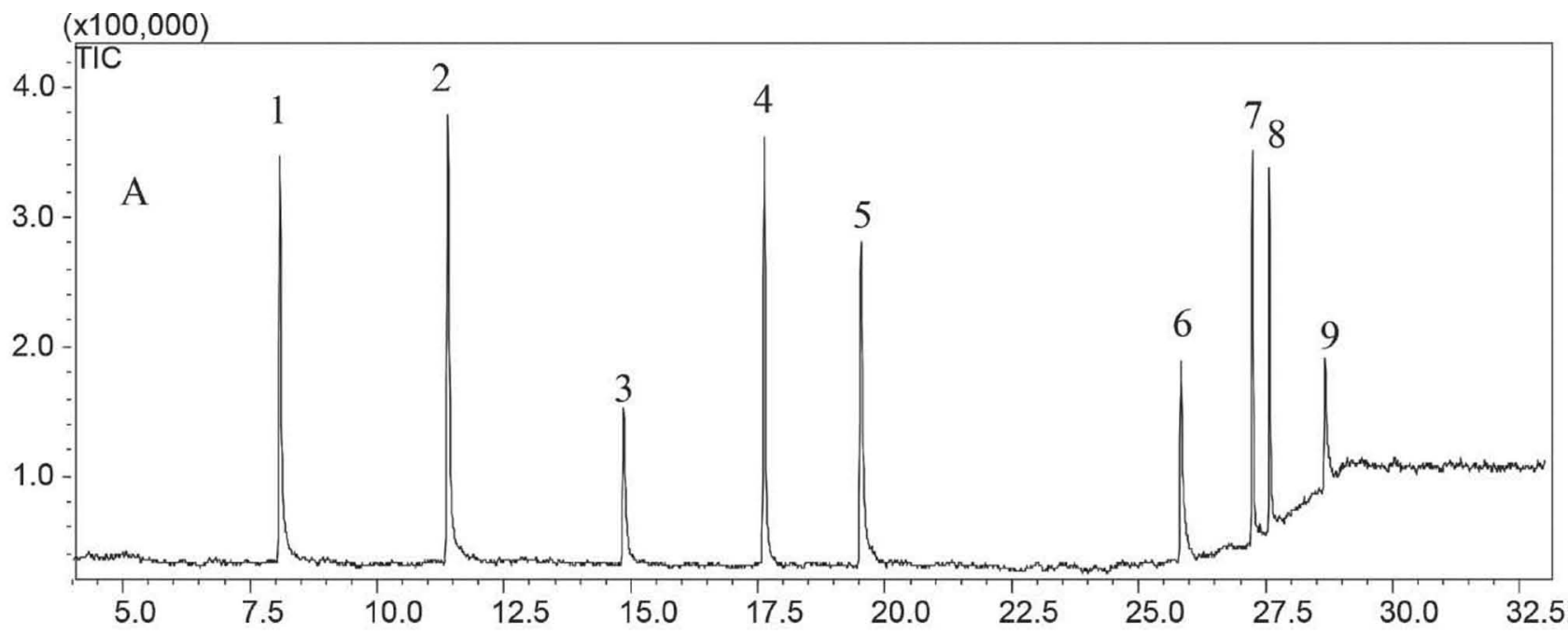

$(\mathrm{x} 1,000,000)$



$(x 1,000,000)$

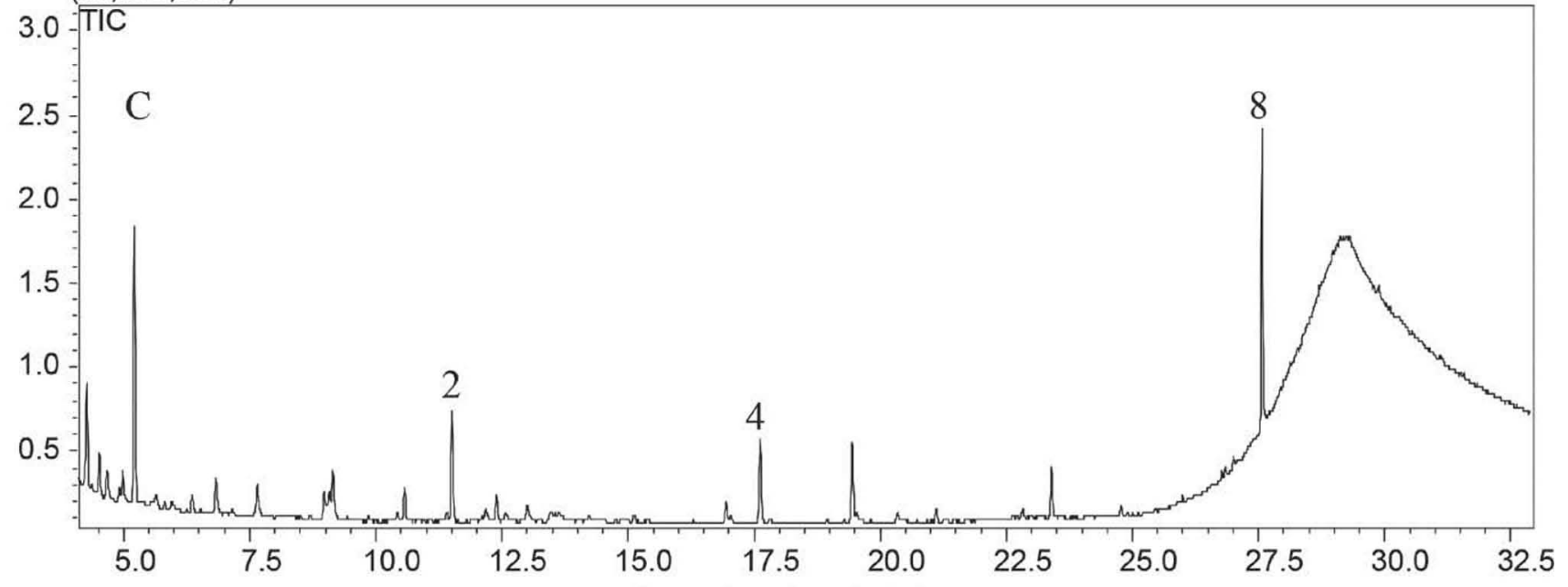

Retention time ( $\mathrm{min}$ )

Figure 1. Gas chromatography-mass spectrometry chromatograms of (A) $25 \mathrm{mg} / \mathrm{L}$ standards and extracts for (B) free phthalates and (C) total phthalates. Peak $1=$ dimethyl phthalate $(\mathrm{DMP}) ; 2=$ diethyl phthalate $(\mathrm{DEP}) ; 3=$ diallyl phthalate $(\mathrm{DAP}) ; 4=$ diisobutyl phthalate (DIBP); $5=$ dibutyl phthalate (DBP); $6=$ benzyl butyl phthalate (BBP); $7=$ dicyclohexyl phthalate (DCHP); $8=$ bis $(2$-ethylhexyl) phthalate $(\mathrm{DEHP}) ; 9$ = di-n-octyl phthalate (DNOP). 
Table 1. Retention times, linearity, identified ions, and sensitivity of studied phthalates

\begin{tabular}{|c|c|c|c|c|c|c|}
\hline Analyte $^{1}$ & $\begin{array}{c}\text { Retention } \\
\operatorname{time}^{2}(\min )\end{array}$ & Calibration curve $^{3}$ & $\begin{array}{l}\text { Coefficient } \\
\left(\mathrm{R}^{2}\right)\end{array}$ & Identified ions $(m / z)$ & $\begin{array}{c}\text { Limit of } \\
\text { detection } \\
(\mathrm{ng} / \mathrm{g})\end{array}$ & $\begin{array}{c}\text { Limit of } \\
\text { quantification } \\
(\mathrm{ng} / \mathrm{g})\end{array}$ \\
\hline DMP & $9.42 \pm 0.01$ & $\mathrm{y}=6.0580 \mathrm{x}-5.1833$ & 0.9965 & $194,163,133,77$ & 0.16 & 0.53 \\
\hline DAP & $16.08 \pm 0.01$ & $\mathrm{y}=6.2920 \mathrm{x}+7.3333$ & 0.9935 & $246,207,189,149$ & 0.32 & 1.01 \\
\hline DIBP & $18.51 \pm 0.01$ & $\mathrm{y}=6.0780 \mathrm{x}-4.4833$ & 0.9974 & $278,223,205,149$ & 0.12 & 0.40 \\
\hline DBP & $20.50 \pm 0.01$ & $\mathrm{y}=6.5160 \mathrm{x}-5.9000$ & 0.9961 & $278,249,223,205,149$ & 0.28 & 0.91 \\
\hline DNOP & $29.12 \pm 0.01$ & $\mathrm{y}=5.6583 \mathrm{x}-17.2000$ & 1.0000 & $390,281,207,149$ & 0.36 & 1.20 \\
\hline
\end{tabular}

${ }^{1} \mathrm{DMP}=$ dimethyl phthalate; $\mathrm{DEP}=$ diethyl phthalate; $\mathrm{DAP}=$ diallyl phthalate; $\mathrm{DIBP}=$ diisobutyl phthalate; $\mathrm{DBP}=$ dibutyl phthalate; $\mathrm{BBP}$ = benzyl butyl phthalate; DCHP = dicyclohexyl phthalate; DEHP = bis(2-ethylhexyl) phthalate; DNOP = di-n-octyl phthalate.

${ }^{2}$ Expressed as mean \pm SD based on 6 determinations.

${ }^{3}$ Where $\mathrm{y}$ is the peak area of phthalate standards, and $\mathrm{x}$ is the concentration of standards.

Table 2. Extraction recoveries ${ }^{1}(\%)$ of 9 phthalate standards added to milk samples

\begin{tabular}{lrcr}
\hline & \multicolumn{3}{c}{ Added concentration $(\mathrm{ng} / \mathrm{g})$} \\
\cline { 2 - 4 } Standard $^{2}$ & \multicolumn{1}{c}{10} & \multicolumn{1}{c}{50} & \multicolumn{1}{c}{200} \\
\hline DMP & $82.4 \pm 1.3$ & $85.0 \pm 1.2$ & $87.0 \pm 0.9$ \\
DEP & $91.1 \pm 2.6$ & $89.0 \pm 1.3$ & $92.0 \pm 0.7$ \\
DAP & $88.3 \pm 1.6$ & $83.6 \pm 0.9$ & $85.6 \pm 1.1$ \\
DIBP & $80.0 \pm 0.9$ & $89.5 \pm 1.3$ & $82.7 \pm 0.3$ \\
DBP & $94.4 \pm 2.5$ & $88.5 \pm 1.2$ & $89.3 \pm 1.2$ \\
BBP & $83.5 \pm 1.5$ & $99.4 \pm 1.6$ & $102.5 \pm 0.9$ \\
DCHP & $85.9 \pm 1.6$ & $88.2 \pm 2.0$ & $98.6 \pm 1.3$ \\
DEHP & $91.1 \pm 2.0$ & $91.2 \pm 1.7$ & $101.5 \pm 2.0$ \\
DNOP & $107.5 \pm 2.8$ & $90.5 \pm 0.6$ & $92.8 \pm 1.8$ \\
DElC
\end{tabular}

${ }^{1}$ Calculated as extracted total phthalates and expressed as mean $\pm \mathrm{SD}$ based on 3 analyses.

${ }^{2} \mathrm{DMP}=$ dimethyl phthalate; $\mathrm{DEP}=$ diethyl phthalate; $\mathrm{DAP}=$ diallyl phthalate; DIBP $=$ diisobutyl phthalate; $\mathrm{DBP}=$ dibutyl phthalate; $\mathrm{BBP}=$ benzyl butyl phthalate; $\mathrm{DCHP}=$ dicyclohexyl phthalate; DEHP $=$ bis $(2$-ethylhexyl) phthalate; DNOP $=$ di-n-octyl phthalate.

\section{CONCLUSIONS}

We developed and successfully applied a method for extraction and determination of free and bound phthalate esters in milk samples for use in commercial whole milk products. Bis(2-ethylhexyl) phthalate (DEHP) was the most abundant phthalate and it occurred in both free and bound forms, whereas diethyl phthalate (DEP) occurred only in bound form in all milk samples. The concentrations of phthalates in milk samples packaged in plastic materials were much higher than those in metal or glass containers. Thus, plastic packaging materials are the probable source of phthalate contamination in commercial whole milk products, and a considerable amount of the phthalates that migrate from the packaging exists in bound form.

Table 3. Concentrations ${ }^{1}$ of the free and bound phthalates in whole milk samples in different packaging materials

\begin{tabular}{|c|c|c|c|c|c|c|}
\hline Phthalate $^{2}$ & \multicolumn{3}{|c|}{ Free form (ng/g) } & \multicolumn{3}{|c|}{ Bound form ${ }^{3}$ (ng/g) } \\
\hline DMP & $\mathrm{ND}^{4}$ & ND & ND & ND & ND & ND \\
\hline DAP & ND & ND & ND & ND & ND & ND \\
\hline DIBP & $4.8 \pm 0.6$ & $5.9 \pm 0.8$ & $23.9 \pm 1.3$ & $3.1 \pm 0.5$ & $6.0 \pm 0.6$ & $26.3 \pm 1.6$ \\
\hline DBP & ND & ND & ND & ND & ND & ND \\
\hline DEHP & $8.8 \pm 0.7$ & $6.6 \pm 0.5$ & $79.3 \pm 2.6$ & $6.0 \pm 1.5$ & $6.7 \pm 0.8$ & $77.1 \pm 5.6$ \\
\hline DNOP & ND & ND & ND & ND & ND & ND \\
\hline
\end{tabular}

${ }^{1}$ Expressed as mean \pm SD based on 5 determinations.

${ }^{2} \mathrm{DMP}=$ dimethyl phthalate; $\mathrm{DEP}=$ diethyl phthalate; $\mathrm{DAP}=$ diallyl phthalate; $\mathrm{DIBP}=$ diisobutyl phthalate; $\mathrm{DBP}=$ dibutyl phthalate; $\mathrm{BBP}$ = benzyl butyl phthalate; DCHP = dicyclohexyl phthalate; DEHP = bis(2-ethylhexyl) phthalate; DNOP = di-n-octyl phthalate.

${ }^{3}$ Calculated by subtracting free phthalates from total phthalates.

${ }^{4}$ Not detected. 

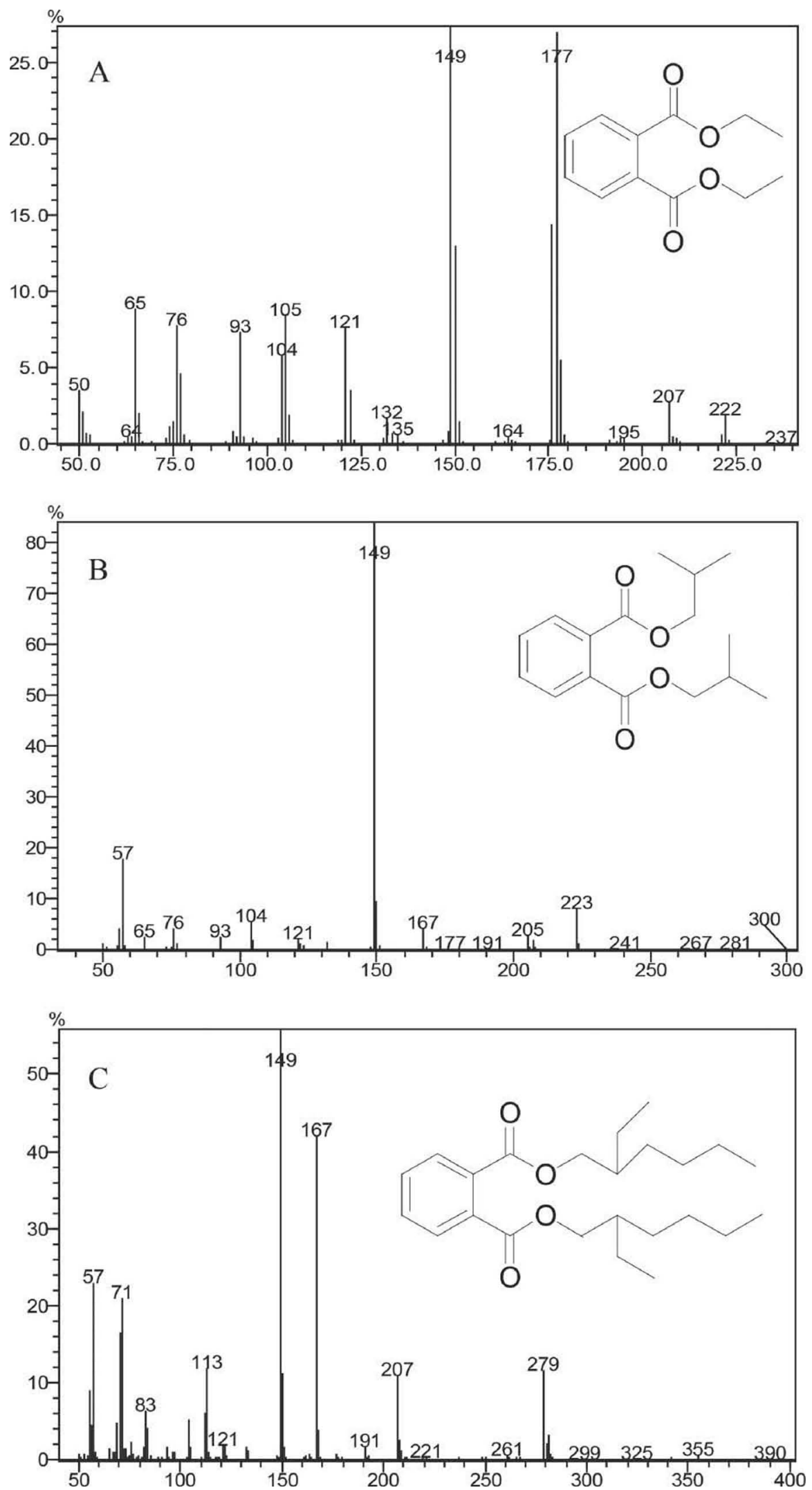

Figure 2. Mass spectra of the identified phthalates in extracts of milk samples: (A) diethyl phthalate (DEP), (B) diisobutyl phthalate (DIBP), and (C) bis(2-ethylhexyl) phthalate (DEHP). 


\section{ACKNOWLEDGMENTS}

The research project was jointly supported by the National Natural Science Foundation of China (21477088; 21207102) at Beijing City, the Qianjiang Talents Plan of Science Technology Department of Zhejiang Province (2013R10067) at Hangzhou City, Zhejiang Scientific and Technological Innovation Fund \& Xinmiao Talents Projects (2014R424028) at Hangzhou City, and National Innovation Program for Undergraduate Students at Wenzhou University (201410351013).

\section{REFERENCES}

Abraham, M. H., and W. E. Acree Jr.. 2015. Physicochemical and biochemical properties for the dialkyl phthalates. Chemosphere 119:871-880

Cao, X. L. 2008. Determination of phthalates and adipate in bottled water by headspace solid-phase microextraction and gas chromatography/mass spectrometry. J. Chromatogr. A 1178:231-238.

Carrillo, J. D., C. Salazar, C. Moreta, and M. Tena. 2007. Determination of phthalates in wine by headspace solid-phase microextraction followed by gas chromatography-mass spectrometry: Fibre comparison and selection. J. Chromatogr. A 1164:248-261.

Casajuana, N., and S. Lacorte. 2004. New methodology for the determination of phthalate esters, bisphenol A, bisphenol A diglycidyl ether, and nonylphenol in commercial whole milk samples. J. Agric. Food Chem. 52:3702-3707.

Fasano, E., F. Bono-Blay, T. Cirillo, P. Montuori, and S. Lacorte. 2012. Migration of phthalates, alkylphenols, bisphenol A and di(2ethylhexyl)adipate from food packaging. Food Contr. 27:132-138.

Feás, C., M. Alonso, E. Vazquez, P. Hermelo, and P. Barrera. 2008 Phthalates determination in physiological saline solutions by HPLC-ES-MS. Talanta 75:1184-1189.

Feng, Y., J. Zhu, and R. Sensenstein. 2005. Development of a headspace solid-phase microextraction method combined with gas chromatography mass spectrometry for the determination of phthalate esters in cow milk. Anal. Chim. Acta 538:41-48.

Ferguson, K. K., R. Loch-Caruso, and J. Meeker. 2011. Urinary phthalate metabolites in relation to biomarkers of inflammation and oxidative stress: NHANES 1999-2006. Environ. Res. 111:718-726.

Fierens, T., M. Van Holderbeke, H. Willems, S. D. Henauw, and I. Sioen. 2012. Phthalates in Belgian cow's milk and the role of feed and other contamination pathways at farm level. Food Chem. Toxicol. 50:2945-2953.

Fritz, J. W., and Y. Zuo. 2007. Simultaneous determination of tetracycline, oxytetracycline, and 4-epitetracycline in milk by highperformance liquid chromatography. Food Chem. 105:1297-1301.

Guo, J. 2008. Determination of phthalate esters in river, tap, rain and snow water. MS Thesis. University of Massachusetts, Dartmouth.

Guo, Y., Z. Zhang, L. Liu, Y. Li, N. Ren, and K. Kannan. 2012. Occurrence and profiles of phthalates in foodstuffs from China and their implications for human exposure. J. Agric. Food Chem. 60:6913-6919.

Hauser, R., J. Meeker, and N. Singh. 2007. DNA damage in human sperm is related to urinary levels of phthalate monoester and oxidative metabolites. Hum. Reprod. 22:688-695.
Hsieh, S., C. Wang, and S. Wu. 2013. Microemulsion electrokinetic chromatography for analysis of phthalates in soft drinks. Food Chem. 141:3486-3491.

Hu, X., W. Shi, S. Wei, X. Zhang, J. Feng, G. Hu, S. Chen, J. Giesy, and H. Yu. 2013. Occurrence and potential causes of androgenic activities in source and drinking water in china. Environ. Sci Technol. 47:10591-10600.

Jenkins, T. C., and M. A. McGuire. 2006. Major advances in nutrition Impact on milk composition. J. Dairy Sci. 89:1302-1310.

Jia, W., X. Chu, Y. Ling, J. Huang, and J. Chang. 2014. Analysis of phthalates in milk and milk products by liquid chromatography coupled to quadrupole Orbitrap high-resolution mass spectrometry. J. Chromatogr. A 1362:110-118.

Kamrin, M. A. 2009. Phthalate risks, phthalate regulation, and public health: A review. J. Toxicol. Environ. Health B Crit. Rev. 12:157174.

Khedr, A. 2013. Optimized extraction method for LC-MS determination of bisphenol A, melamine and di(2-ethylhexyl) phthalate in selected soft drinks, syringes, and milk powder. J. Chromatogr. B Analyt. Technol. Biomed. Life Sci. 930:98-103.

Kimber, I., and R. J. Dearman. 2010. An assessment of the ability of phthalates to influence immune and allergic responses. Toxicology 271:73-82

López-Carrillo, L., R. Hernández-Ramírez, A. Calafat, L. Torres-Sánchez, M. Galván-Portillo, L. Needham, R. Ruiz-Ramos, and M. Cebrián. 2010. Exposure to phthalates and breast cancer risk in Northern Mexico. Environ. Health Perspect. 118:539-544.

Shen, H. Y. 2005. Simultaneous screening and determination eight phthalates in plastic products for food use by sonication-assisted extraction/GC-MS methods. Talanta 66:734-739.

Soyeurt, H., I. Misztal, and N. Gengler. 2010. Genetic variability of milk components based on mid-infrared spectral data. J. Dairy Sci. 93:1722-1728.

Van Holderbeke, M., L. Geerts, G. Vanermen, K. Servaes, I. Sioen, S. D. Henauw, and T. Fierens. 2014. Determination of contamination pathways of phthalates in food products sold on the Belgian market. Environ. Res. 134:345-352.

Ventrice, P., D. Ventrice, E. Russo, and G. Sarro. 2013. Phthalates: European regulation, chemistry, pharmacokinetic and related toxicity. Environ. Toxicol. Pharmacol. 36:88-96.

Wang, C., and Y. Zuo. 2011. Ultrasound-assisted hydrolysis and gas chromatography-mass spectrometric determination of phenolic compounds in cranberry products. Food Chem. 128:562-568.

Xu, D., X. Deng, E. Fang, X. Zheng, Y. Zhou, L. Lin, L. Chen, M. Wu, and Z. Huang. 2014. Determination of 23 phthalic acid esters in food by liquid chromatography tandem mass spectrometry. J. Chromatogr. A 1324:49-56.

Zhang, K., J.W. Wong, D.G. Hayward, M. Vaclavikova, C.D. Liao, and M.W. Trucksess. 2013. Determination of mycotoxins in milkbased products and infant formula using stable isotope dilution assay and liquid chromatography tandem mass spectrometry. J. Agric. Food Chem. 61:6252-6273.

Zuo, R., S. Zhou, Y. Zuo, and Y. Deng. 2015. Determination of creatinine, uric acid and ascorbic acid in bovine milk and orange juice by hydrophilic interaction HPLC. Food Chem. 182:242-245.

Zuo, Y., C. Wang, Y. Lin, and Y. Deng. 2008. Simultaneous determination of anthraquinones in radix Polygoni multiflori by capillary gas chromatography coupled with flame ionization and mass spectrometric detection. J. Chromatogr. A 1200:43-48. 